\title{
Nachbemerkung und Dank
}

Das vorliegende Buch geht zurück auf ein Typoskript, das im November 1991 dem damaligen Fachbereich 7 (Philosophie) der Westfälischen Wilhelms-Universität Münster als Habilitationsschrift vorgelegt wurde. Aus verschiedenen Gründen, die nichts mit dem Thema des Buchs zu tun haben, hat sich die Überarbeitung für die Drucklegung sehr verzögert. Daß die Schrift nun im Clementi-Jahr 2002 nach einer durchgreifenden Überarbeitung doch endlich erscheint, habe ich vor allem dem freundschaftlichen wie aufmunterndem Drängen von Uwe Schweikert (Stuttgart) zu danken. Im Rückblick auf die Erstellung der ersten Fassung von 1991 sei Klaus Hortschansky (Münster) ganz herzlich gedankt, der sich als damaliger Direktor des Musikwissenschaftlichen Seminars der Universität Münster in besonderer Weise des Fortgangs dieses Projekts annahm, ihm jede erdenkliche Hilfe zuteil werden ließ und die Ausarbeitung durch eine Geschäftsverteilung wesentlich erleichterte, die mir in großzügiger Weise den nötigen Freiraum für die Niederschrift ließ. Laurenz Lütteken (damals Münster, heute Zürich) ließ mich in fruchtbarem Gedankenaustausch an seinen Überlegungen zur nord- und mitteldeutschen Musikgeschichte des 18. Jahrhunderts teilhaben, war immer ein aufgeschlossener Diskussionspartner und packte auch bei der Lösung einiger technischer Probleme tatkräftig mit an. Der Gedankenaustausch mit Andreas Staier (Köln) eröffnete mir neue Fragen und Perspektiven. Balthasar Müller (damals Sassenberg, heute St. Ursanne) half in allen schwierigen Phasen mit geduldigen Ermutigungen und pragmatischer Lebenserfahrung.

Vielen meist anonym gebliebenen Bibliothekarinnen und Bibliothekaren in Münster (Westfalen), Cambridge, London, Wolfenbüttel, Berlin, Paris, Bern und Basel habe ich für kompetente Hilfsbereitschaft zu danken, vor allem aber den Mitarbeitern des Instituts für Musikwissenschaft der Universität Bern. Ohne ihre engagierte Unterstützung hätte der Band nicht in die vorliegende Form gebracht werden können: Reto Schürch besorgte die äußerst sorgfältige Erstellung der ebenso zahlreichen wie kniffligen Notenbeispiele; Thomas Gerlich und Arne Stollberg waren höchst aufmerksame und kritische Leser verschiedener Typoskriptfassungen; Edith Keller und Daniel Allenbach halfen bei der Umbruchkorrektur. Die materiellen Voraussetzungen dafür, daß der Band in der vorliegenden Form erscheinen kann, stellte die Stiftung zur Förderung der wissenschaftlichen Forschung an der Universität Bern bereit, der abschließend für den großzügigen Druckkostenzuschuß gedankt sei. 